\title{
Patterns of Vietnamese buying behaviors on luxury branded products
}

\author{
Ho Huy Tuu*
}

Svein Ottar Olsen

Le Chi Cong

* Correspondence author

Ho Huy Tuu, Lecturer, Dr., Economics Faculty, University of Nhatrang, N-02 Nguyen Dinh Chieu, Nhatrang, Vietnam, phone: +84 908250608, e-mail: tuuhh@ntu.edu.vn

Svein Ottar Olsen, Professor, Tromsø University Business School, University of Tromsø, N9037 Tromsø, Norway, phone: + 0497403132, e-mail: svein.o.olsen@uit.no

Le Chi Cong, Lecturer, Dr., Economics Faculty, University of Nhatrang, N-02 Nguyen Dinh Chieu, Nhatrang, Vietnam, Phone: +84 983128380, e-mail: conglechi@ntu.edu.vn

Target journal: Asia Pacific Journal of Marketing and Logistics

Paper type: Research paper.

December 2016 


\title{
Patterns of Vietnamese buying behaviors on luxury branded products
}

\author{
Abstract \\ Purpose - This study discusses and tests the combined effects of openness to experience and \\ power, and the moderator effects of social norms and perceived resources on the choice of luxury \\ attributes for branded products (CLA) in Vietnam. \\ Design/methodology/approach - Based on a self-administered survey data of 207 Vietnamese \\ consumers, a structural equation modelling approach for moderator analysis with latent \\ constructs is used to test the hypotheses. \\ Findings - Openness to experience and power have both direct and interactive positive \\ influences on the choice of luxury product attributes. In particular, the effect of openness to \\ experience is weakened by the negative moderator effect of social norms, but the effect of power \\ is strengthened by the positive moderator effect of perceived resources. The inclusion of \\ interactions increases the explained variance of the choice of luxury product attributes from 24.8 \\ $\%$ to $35.8 \%$.
}

Research limitations/implications - Future studies would benefit to investigate other personality traits (e.g., extroversion or agreeableness), personal values (e.g., achievement), social norms (e.g., descriptive norms) and resources (e.g., time).

Practical implications - The study findings suggest that brand managers should attend the how individual and social factors interacts in explaining the choice of luxury product attributes. Originality/value - This study is the first discussing, testing and finding empirical evidence supporting the combined effects of openness to experience and power on the choice of luxury product attributes as well as moderator effects in these relationships.

Keywords: Openness to experience, power, luxury attributes, social norms, perceived resources, moderator effect. 


\section{Introduction}

Individual traits of personality and value have been shown to be important determinants of product or brand choice (Graeff, 1997) including luxury consumption (Amatulli and Guido, 2011; Park, Rabolt and Jeon, 2008; Truong and McColl, 2011; Yim and Sauer, 2014). Just as consumers often make purchase decisions based on a product or brand's symbolic meanings, the perception of product attributes may be a function of the demonstration and expression of consumers' personalities and personal values (Sirgy et al., 1991). Previous studies have tested the relationship between luxury product/brand attitude or choice and different individual personal characteristics, such as self-fulfilment/self-confidence (Amatulli and Guido, 2011), personal growth, self-esteem (Truong and McColl, 2011), self-directed symbolism (Shukla, Singh and Banerjee, 2015), ethnocentrism, conformity, need for uniqueness (Park et al., 2008), modernity, eccentricity, opulence, elitism (Heine, 2009), materialism, hedonism and social connections (Chen and Kim, 2013).

The relationship between personality traits (extroversion, agreeableness, conscientiousness, neuroticism and openness - in Five-Factor Model) and consumer behaviors has been explored in the context of non-luxury products or brands, but only a few studies found significant relationships between luxury consumption and personality traits (e.g., public self-consciousness, self-esteem; Giovannini, Xu and Thomas 2015). Openness to experience has been found to be most closely linked to the luxury attributes of a product or brand, such as creative, innovative, emotional, aesthetic, affective and symbolic aspects of a brand or product (Holt and Cameron, 2010; Matzler, Bidmon and Grabner-Krauter, 2006; Miller and Mills, 2012; Olver and Mooradian, 2003), while similar evidence for other personality traits are very rare. Therefore, this study focuses on openness to experience and treats this trait as a conceptually independent construct from others (Costa and McCrae, 1985; Goldberg, 1992). 
Furthermore, there is little understanding of how personality traits and personal values might jointly influence consumers' product choices (Mulyanegara and Tsarenko, 2009). The existing literature (Bilsky and Schwartz, 1994; Roccas et al., 2002) shows that openness to experience is highly compatible and overlapped with the personal values of self-direction, universalism, stimulation, but conflicts with conformity, tradition, and security. However, how openness to experience relates with power, in particular their interaction influencing on consumer behavior, is unexplored. For example, luxury products are suggested to be innovative and creative (Miller and Mills, 2012), to signal self-presentation (Amatulli and Guido, 2011), individualism (Yim and Sauer, 2014) and being attached to the persons who are rich, powerful and open in seeking such products to show their self-image (Heine, 2009; Zou et al., 2014). Thus, this study aims to contribute to the existing literature by exploring how and why the combination of openness to experience and power influence the choice of luxury attributes (CLA) for branded products in Vietnam. Answering the two unexplored questions in the literature, "Do openness to experience and power associate with the choice of luxury attributes?" and, "Do openness to experience and power interact with each other to influence the choice of luxury attributes?" form the first purpose of this study.

Customer choice is not always an individual phenomenon, but includes complex social interactions because in many cases customers have to reconcile different choices, share social cognitions or feelings and comply with social norms and the expectations of others (Amabile, 1996; Olsen and Grunert, 2010). The literature also shows that personal traits can interact with social influences to affect individuals' attitudes and behaviors and that the effect of traits differs depending on how individuals perceive such social influences positively or negatively (George and Zhou, 2001). Social conflicts are existing in Vietnam (Cong, Olsen and Tuu, 2012), in particularly when social concerns focus more on basic than growth needs (Tuu and Olsen, 2010). 
This study contributes to the literature by exploring how personal traits (e.g., openness to experience and power) relate to the choice of luxury product attributes (CLA) of branded products under the negatively moderating effect of social norms.

A few previous studies have suggested that the relationship between personal traits and individual attitudes or behaviors is moderated by individual resources (Chen, Lee-Chai and Bargh, 2001; Lönnqvist et al., 2011). Based on value activation perspectives (Higgins, 1996) as well as the theory of resource allocation (Roberts and Dant, 1991), this study extends prior research by suggesting that perceived resources such as money, knowledge and social power may activate personal traits (e.g., openness to experience and power) to enhance their effects on CLA.

In summary, this study aims to contribute to the literature by three folds. First, it discusses and investigates the combined role of the openness to experience and power traits in explaining CLA. Second, it tests whether social norms negatively moderate the association between openness to experience and power traits and CLA. Finally, it discusses and tests perceived resources as a positive moderator of the effect of openness to experience and power traits on CLA. While marketers have been challenged to remove a strong focus on traditional functional product attributes and price, an understanding of individual traits and values in relation to selected unique, symbolic and innovative product attributes are important for developing customized products and new marketing tools that enable marketers to better serve and satisfy emerging and challenging desires of individual customers (Fitzmaurice and Comegys, 2006; Keller, 2009; Kotler, 2000; Shukla et al., 2015; Tsai, 2005). This knowledge is essential for the managers of premium branded products, particular for those who want to develop products with a luxury image with a strong positioning based on individual traits and values (e.g., power and openness; Okonkwo, 2009). 
This study uses the survey data from consumers in two cities in Vietnam and a structural equation modelling for moderator analysis with latent constructs (Ping, 1996) to test a proposed model and research the hypotheses.

\section{Conceptual framework}

\section{Luxury positioning and the choice of luxury attributes}

The concept of luxury is difficult to define because it is highly subjective, situationally and experientially contingent and depends on the individual and social needs of the consumer (Kapferer and Bastien, 2009; Vigneron and Johnson, 1999). Amatulli and Guido (2011) propose that a luxury is formed by both external and internal values and thus it includes both internal and external attributes. Internal attributes are typically related to social positioning and status symbol perceptions, while external attributes are typically related to the search for pleasure, originality and perfection (Vickers and Renand, 2003). Consumers can "externalize" luxury to show others how much they paid (high price), to emulate people they admire or because they are pushed by a competitive spirit, while they can also "internalize" luxury if motivated by aesthetic pleasures, or cultural or personal sensibility to certain values (Amatulli and Guido, 2011; Tsai, 2005). Vigneron and Johnson (1999) propose that interpersonal and personal effects coexist in luxury consumption. Social value belongs to the former category and the latter contains hedonic value and quality value. The former is externally driven by the desire to impress others, whereas the latter is internally driven and expresses self-fulfilment goals.

Generally, consumers' luxury perceptions should follow an integrative understanding of luxury as it has become more complex and diverse (Dubois, Czellar and Laurent, 2005). Some researchers have developed multidimensional perspective of luxury as a reflective second-order construct to address this trend. Based on a firm-centric approach, Nueno and Quelch (1998) identify the common luxury characteristics that include consistent delivery of premium quality, 
expense, craftsmanship, a recognisable style or design, exclusivity, emotional appeal, excellence, reputation, uniqueness and the like. Similarly, based on a consumer approach, Vigneron and Johnson (2004) detail five dimensions that consumers may use to differentiate luxury and nonluxury products or brands, including perceived conspicuousness, uniqueness, quality, hedonism and perceived extended self.

An alternative approach to conceptualizing luxury is evident in another stream of research (e.g., Berthon et al., 2009; Vickers and Renand, 2003). In particular, Vickers and Renand (2003) propose that luxury and non-luxury products can be differentiated according to the functional, experiential and symbolic interactional dimensions of a product. They describe the functional dimension as a set of product features that solves extrinsic consumption needs through physical and service attributes (e.g., product quality), experientialism as product features that stimulate sensory pleasure and the "symbolic interactional" dimension as product components that are related to status and affiliation with a desired group. In addition, there is a consensus among researchers that luxury is associated with originality, creative excellence, uniqueness, creative imagination, innovative design and creative quality, which links with the symbols, logos and package design (Kapferer and Bastien, 2009; Keller, 2009; Vigneron and Johnson, 1999; 2004). Innovation is associated with originality (scarcity), uniqueness, creativity, and slight imperfections in handmade products (Nueno and Quelch, 1998). Therefore, to activate potential individual traits of openness to experience, this study includes an innovative and creative dimension for a luxury product's attributes (Holt and Cameron, 2010; Miller and Mills, 2012).

Given the multidimensional perspective of luxury construct, Wiedmann, Hennigs and Siebels (2007) suggested that it is important to combine a set of luxury dimensions into one single model as a reflective second-order construct (Vigneron and Johnson, 2004), rather than treating each luxury dimension separately. This is because the motives for luxury brand consumption are not 
simply tied to a set of social aspects of displaying status, success, distinction and the human desire to impress other people, but also depend on the nature of functional, experiential and individual utilities of a certain luxury brand (Wiedmann et al, 2007). This study also adopts the multidimensional perspective of luxury as a reflective second-order construct to propose that luxury and non-luxury products can be differentiated according to functional, experiential, symbolic interactional and innovative and creative dimensions (Kapferer and Bastien, 2009; Keller, 2009; Nueno and Quelch, 1998; Vigneron and Johnson, 1999; 2004; Vickers and Renand, 2003; Wiedmann et al., 2007). In this view, CLA is considered as a second-order latent structure with the four luxury attribute dimensions as the first-order latent constructs or endogenous variables (Vigneron and Johnson, 2004; Wiedmann et al, 2007).

In relation to the choice of product attributes, consumers have often developed phased decision-making strategies to simplify their decision making (Johnson, 1989). An integral component of these phased decision-making strategies is the formation of a downsized subset of products or brands - the consideration set - from which a product/brand is chosen (Nedungadi, 1990). Of those products/brands held within the consideration set, similarities in terms of salient attributes or benefits have been identified as the significant differentiator in facilitating choice (Ballantyne, Warren and Nobbs, 2006). For example, a luxury watch advertisement in www.ebay.com (Ebay, 2015) says that a luxury watch can speak volumes about a range of attributes that define a customer's individual traits, and once a customer has arrived at a picture of selected luxury watch attributes, he/she would go through the different watch elements to determine which combination of features suit him/her best.

Berthon et al. (2009) argue further that there is no absolute differentiation between luxury and non-luxury, but rather that they exist on a continuum. They note that the functional, symbolic, social, experiential and innovative attributes of luxury are contextual and may change 
over time depending on the individual and on socio-cultural beliefs. Based on the above discussion, this study defines CLA as consumers' behavioral predisposition in their decision making to choose those attributes which prompt a luxury product to fulfil consumers' individual goals in a specific consumption context: luxury branded products. Thus, CLA expresses consumers' expected evaluations of luxury attributes on a continuum of non-luxury to luxury associated with their choice of branded products in a product category (Ballantyne et al., 2006; Berthon et al., 2009; Nedungadi, 1990).

\section{Openness to experience}

Openness to experience is a personality trait that describes the extent to which individuals are imaginative, sensitive to aesthetics, curious, independent thinkers and amenable to new ideas, experiences and unconventional perspectives (McCrae and Costa, 1997). Individuals with a high openness to experience have experientially richer lives and are willing to entertain novel ideas and unconventional values and emotions more keenly than do closed individuals (Costa and McCrae, 1992; Matzler et al., 2006). Most previous studies suggest that openness to experience is the trait that may be most closely related to creativity and innovation (McCrae and Costa, 1997), which are among the main characteristics in some definitions of luxury (Holt and Cameron, 2010; Miller and Mills, 2012). A few previous studies have suggested a positive association between openness to experience and emotional, aesthetic and symbolic aspects of consumption (i.e., the symbolic interactional attribute of luxury) and the affective aspects (i.e., the experiential attribute of luxury) (Matzler et al., 2006; Olver and Mooradian, 2003). Generally, there are highly compatible associations between the aspects of openness to experience and the dimensions of a luxury, which increases the fit between individuals with high openness to experience and luxury product attributes. Thus, the following hypothesis is suggested: 
H1. Openness to experience is positively associated with CLA.

Power

Personal values and the individual's value system have long been accepted as having a major influence on patterns of consumption for products supporting those values (Pitts and Woodside, 1991). Personal values are suggested to comprise standards or criteria influencing the evaluations of a product/brand and the assessment of the relative importance of various attributes and benefits determining product/brand choice (Vinson, Scott and Lamont, 1977). Thus, it is posited that the attractiveness of choice options is systematically correlated with related personal values in that a choice may be influenced by determining the attractiveness of outcomes that are relevant to those values (Verplanken and Holland, 2002).

Power is a type of motivational goal expressing social status and prestige, control or dominance over people and resources (Schwartz, 1992). Individuals who pursue power may engage in luxury consumption to emulate the consumption patterns of those who are directly above them in the social hierarchy (Truong and McColl, 2011). Thus, products that are of high quality, expensive, unique, high grade or have a good reputation (i.e., luxury attributes) may fit the goals of consumers who pursue power (Solomon and Douglas, 1987). Therefore, it is possible that individuals with a high valuation of power will tend to choose products with attributes reflecting high luxuriousness to a greater extent than those with a lower valuation of power. Consequently, this study expects to contribute to the literature by suggesting that:

H2. Power is positively associated with CLA.

\section{Interaction between power and openness to experience}

Roccas et al. (2002) propose that people try to show their personality in ways consistent with their values and that a personality trait is likely to increase the degree of a goal (e.g., value) that trait serves. In addition, Bilsky and Schwartz (1994) argue that personal values (e.g., power) and 
traits (e.g., openness to experience) can interact if the traits are inferred from behavioral patterns aimed at satisfying growth needs (e.g., choosing a luxury product) and that the person characterized by those personality traits is likely to attribute high importance to those values. Because both power and openness to experience are suggested to link behavior patterns to satisfying high-order needs (e.g., Matzler et al., 2006; McCrae and Costa, 1997), the interaction between power and openness to experience may occur to influence CLA. However, only a few empirical evidence supporting the interaction between power and openness to experience influencing behaviors are found in the literature (e.g., Peterson et al., 2003), this study contributes by proposing that:

H3. Openness to experience and power interact to positively influence CLA.

\section{The moderating effect of social norms}

Social norms are generally supposed to capture an individual's perception that important others in his or her social environment wish or expect him or her to behave in a certain way (Ajzen, 1991). Thus, this study defines social norms as normative influences from socially proximal referents operating in the individual's immediate social network, such as colleagues, neighbours, or the close social community. This definition manifests normative influences that require an opportunity for social interaction and thus it appears that luxury attributes that individuals select can be influenced by the reference groups (Wong and Ahuvia, 1998).

A personal trait may lead to a behavior corresponding to the trait only to the extent that significant others approve, but that trait has little or no impact on a behavior if there is a hostile social context (McMillan and Conner, 2003; Umeh and Patel, 2004). Previous studies have also indicated that social norms can be a critical source of the choice of luxury attributes (Escalas and Bettman, 2005; Wong and Ahuvia, 1998). Although consumers tend to imitate the buying behavior of reference groups to which they would like to belong, not every consumer practises 
luxury consumption, but rather may seek non-luxury attributes (Truong and McColl, 2011).

Thus, if luxury attributes are consistent (inconsistent) with social norms, the trait-luxury attribute connection is expected to be stronger (weaker). For example, if a person considers

himself/herself to be open or powerful and his/her social expectations match a luxury product's attributes with that trait symbol, the likelihood of that person choosing the product is high.

Conversely, if a person's product attributes are incongruent with social norms, the association between the trait and the attributes will be reduced (Escalas and Bettman, 2005). For the context of this study, in which social norms seem to follow traditional orientations and incorporate social conflicts (Cong et al., 2012), it is suggested that social norms may play a role as a negative moderator influencing the association between personal traits (e.g., openness to experience and power) and CLA. Thus:

H4a. Social norms are negatively associated with CLA.

H4b. Social norms reduce the association between openness to experience and CLA.

H4c. Social norms reduce the association between power and CLA.

\section{Moderating effects of perceived resources}

Resources broadly include money, knowledge, time, power, prestige and the kinds of interpersonal resources embodied in the concepts of social support and social networks (Mathieson, Peacock and Chin, 2001). Thus, perceived resources as defined in this study are the extent to which an individual believes he or she has personal resources to pursue a goal. This definition of perceived resources is consistent with resource allocation perspectives (Roberts and Dant, 1991).

Previous studies have indicated that perceived resources may activate people's goals (Chen et al., 2001; Lönnqvist et al., 2011). Because personal traits influence behavior when activated, consumers with high resources could exhibit trait-congruent behavior (Lönnqvist et al., 2011; 
Verplanken and Holland, 2002). Consumers allocate a variety of resources to purchase decisions related to expenditures for multiple needs or goals (Roberts and Dant, 1991). In pursuing the fulfilment of personal traits (e.g., power or openness to experience), achieving a state of wellbeing depends on individuals' ability to satisfy their needs (Tsai, 2005). Therefore, it is possible that the more resources consumers have, the greater their ability to allocate their resources to choosing or buying luxury products to fulfil their personal traits. In contrast, regardless of the personal traits pursued by consumers, those with low resources may be constrained in their choice decision, having to purchase non-luxury products to save resources. Although consumers who trade up to luxury attributes to fulfil salient higher needs or goals (e.g., power or openness to experience traits) may not necessarily be wealthy, they will tend to spend their increasing disposable income on luxury (Truong and McColl, 2011). Based on the above discussion, the following hypotheses are suggested:

H5a. Perceived resources are positively associated with CLA.

H5b. Perceived resources increase the association between power and CLA.

H5c. Perceived resources increase the association between openness to experience and CLA.

Based on the hypotheses proposed above, the theoretical model is shown in Figure 1. [Insert Figure 1 about here]

\section{Methods}

\section{Products and subjects}

Perceptions of luxury are a relative experience and strongly culture-bound (Dubois et al., 2005). Therefore, it is useful to explore this phenomenon in an emerging country like Vietnam (Shukla et al., 2015). The luxury branded products with famous brands, such as Omega watches, Mazda cars, Piaggio motorcycles or different types of furniture, were nowadays impressively 
designed and created with more and more luxury attributes to attract customers in a fiercer and fiercer market. Regardless of the income per capita just at low average, a widely spreading materialism speeds up consumers in all parts of the world (Nueno and Quelch, 1998). This is also the case in Vietnam where consumers present their image of high social class by hunting products/brands that symbolize their wealth, social prestige, power and achievement (Breininge, 2015). As such, luxury branded products/brands have become the symbols of choice that fulfill their personality and value traits. For the quite popularity of such products/brands in Vietnam, it is reasonable to expect that consumers will have acquired some product and brand knowledge and developed choice criteria (e.g., salient attributes) before making a choice decision and that they will thus provide reliable and valid responses to the questionnaire.

Data from 207 Vietnamese consumers were collected through convenience sampling in two cities (Nha Trang and Rach Gia) in a self-administered survey at their homes during the spring and summer of 2015. While Nha Trang is one of the most well-known cities in Vietnam attracting millions of tourists annually, Rach Gia is one of the highest growing and emerging cities in Vietnam. Therefore, consumers in these two cities have shown a sharp tendency towards emerging new products and luxury consumption. The respondents were clearly informed that the study concerned luxury branded products and required them to choose one product in a list as an evaluated object. The highest ratios among selected items are watches (27.6\%), furniture (25.1\%), pendulum-clocks (11.4\%), motorcycles (10.3\%), cars (4.7\%) and others. The typical respondents were female (61.4\%), married (58.0\%) and had been educated for 12 years $(87.4 \%)$. Their average age was 34 years, ranging from 20 to 70, and their average income per month was about USD 300.

Measurement of the constructs 
The scale of CLA was measured to include four dimensions reflecting functional, experiential, symbolic and innovative attributes on a 7-point bipolar scale in the form: "Please indicate the level of each product attribute you tend to choose when you buy the selected product...". The respondents were also encouraged to think about a specific favourite product/brand which tend to buy, then rate their perceptions concerning 14 luxury attributes adapted from previous studies (Berthon et al., 2009; Miller and Mills, 2012; Vigneron and Johnson, 2004).

Openness to experience trait was measured on a 7-point Likert-type scale using three items from the International Personality Item Pool scales (Donnellan et al., 2006), the Ten-Item Personality Inventory (Gosling, Rentfrow and Swann, 2003) and the NEO-Five Factor Inventory (Costa and McCrae, 1992). Power was measured to address the general meanings of the single construct of power (Schwartz, 1992) with three items placed arbitrarily among the 12 items of the short inventory of values (Stern et al., 1998) on a 7-point scale ( 1 = opposed to my values to $7=$ of supreme importance).

Social norms were addressed by asking respondents to indicate how much reference groups influence them when they choose or buy the product on a 7-point bipolar scale $(1=$ totally without influence and $7=$ strongly influential). Perceived resources ware measured by asking the respondents to indicate how much money, knowledge and social power (Mathieson et al., 2001) they perceived themselves to have at that time they should decide to choose or buy the product that would fulfil their goals. A 7 -point bipolar scale $(1=$ totally inadequate to $7=$ totally adequate) was used.

Those above scales were tested in a pilot survey with 50 consumers. The primary analytical results showed that all those scales have acceptable reliability with all the values of Cronbach's alpha exceeding the threshold of 0.70 (Hair et al., 2010). However, some bad items (factor 
loadings $<0.3$ ) were also eliminated in this pilot test. It is worth noting that this study used a $7-$ point instead of a 5-point Likert and polar scale to increase the sensitivity of the respondents' responses (Hair et al., 2010). With a sample size of 207 and 23 items measuring the intended constructs, the ratio of cases per item (about 8.8) is higher than the minimum threshold (5.0) for reliability and robust estimations using multivariate analysis like SEM (Hair et al., 2010). In addition, 207 cases used in this study is enough large to avoid nonconvergence or improper solutions that are more likely when the sample size is less than 150 cases (Anderson \& Gerbing 1984; Iacobucci, 2010; Kline, 2010; Marsh and Hau, 1999).

\section{Results}

\section{Validation of measures: reliability and validity}

The constructs were assessed to ensure internal consistency, convergent and discriminant validity by performing confirmatory factor analysis (CFA) using AMOS. The results, summarized in Table 1, indicate that the measurement model fits the data well $\left[\chi^{2}=363.7, p=\right.$ $0.000 ; \mathrm{RMSEA}=0.058 ; \mathrm{GFI}=0.90 ; \mathrm{AGFI}=0.89 ; \mathrm{IFI}=0.90 ; \mathrm{NFI}=0.91 ; \mathrm{CFI}=0.91]$ (Anderson and Gerbing, 1988).

All the composite reliability (CR) measures exceed the minimum value of 0.60 and most of the average variance extracted (AVE) surpass the recommended threshold of 0.50 (Anderson and Gerbing, 1988). In addition, all the values of Cronbach's alpha are higher than 0.70 (Hair et al, 2010). Although the AVE of openness to experience (0.46) is lower than 0.50 , its CR is 0.72 . Therefore, the reliability of openness to experience is acceptable, in particular when previous studies give the same findings (e.g., George and Zhou, 2001; Matzler et al., 2006). The individual item loadings on the constructs are all significant $(p<0.001 ; t$-value $>6)$ with values ranging from 0.59 to 0.96 , showing that the convergent validity of the constructs is acceptable (Steenkamp and van Trijp, 1991). It is worth noting that CFA for the reflective second-order 
construct of CLA indicates an acceptable fit with the data $\left[\chi^{2}(d f=38)=103.3, p<0.000\right.$; GFI $=$ 0.92; $\mathrm{AGFI}=0.91 ; \mathrm{IFI}=0.92 ; \mathrm{NFI}=0.91 ; \mathrm{CFI}=0.92 ; \mathrm{RMSEA}=0.09]($ Bagozzi and Yi, 2012). Thus, this study keeps this reflective second-order construct in testing hypotheses in the next steps.

[Insert Tables 1 and 2 about here]

As shown in Table 2, all the correlations are less than 0.50 and the squared correlation between each of the constructs (highest value 0.42 ) is less than the average variance extracted (AVE) from each pair of constructs (lowest value 0.47), demonstrating discriminant validity (Fornell and Larcker, 1981).

\section{Hypothesis testing}

This study used Ping's (1996) two-step estimation approach for modelling latent variable interactions. First, all the origins of the scales of the constructs were changed by mean-centring to reduce the correlations between the constructs and their interactions (Aiken and West, 1991). Then, the average scores of the indicators of the latent variables in the interactions were multiplied to form interactions. Next, the factor loadings and the error variances of these interacting measures were fixed using particular values based on the formulas provided by Ping (1996), using parameter estimates from the measurement model (Table 1) as inputs (for further detail, see Ping, 1996).

An analytical strategy of nested models in structural equation modelling (SEM) was employed to estimate the effects of the variables and their interactions on CLA (Aiken and West, 1991). Before conducting the analyses, five separate SEM models were run to test the interacting and moderating effects in each equation, including an independent variable (e.g., openness to experience - OE), a moderator (e.g., social norms - SN) and an interaction term between them (e.g., OE x SN) on CLA. Those preliminary analyses indicated that the hypotheses involving 
interaction and moderators were supported by three of the five tests and that the interactions between power and social norms and between perceived resources and openness to experience on CLA were not significant. This means that $\mathrm{H} 4 \mathrm{c}$ and $\mathrm{H} 5 \mathrm{c}$ are not supported by the data. For reasons of parsimony, these interactions were not included in the next analyses. The independent variables and interactions were entered in two blocks and thus two nested models were generated. The Direct Effect Model estimates the direct effects of openness to experience, power, social norms and perceived resources on CLA. The Full Model adds the interaction effect of openness to experience and power, and the moderating effects of social norms and perceived resources on CLA. The results indicate acceptable fit for the two estimated models (GFI $=0.88-$ 0.89; $\mathrm{CFI}=0.90-0.91 ; \mathrm{AGFI}=0.87-0.88 ; \mathrm{IFI}=0.89-0.90 ; \mathrm{NFI}=0.89-0.90 ; \mathrm{RMSEA}=0.06-$ 0.06). Because the estimation results are consistent with each other for the two models, the following conclusions are based on the Full Model (see Table 3).

The direct effects. $\mathrm{H} 1$ and $\mathrm{H} 2$ suggested that openness to experience and power would have a positive effect on CLA. This is a test of the main effects of openness to experience and power on CLA. The results support these hypotheses, indicating a significant positive effect of both openness to experience $(\beta=0.21, t=2.1, p<0.05)$ and power $(\beta=0.34, t=3.4, p<0.001)$ on CLA. These results are necessary for testing further moderating effects on these relationships. Next, H4a and H5a suggested that while social norms have a negative association, perceived resources have a positive association with CLA. The results do not support H4a by indicating a nonsignificantly negative effect of social norms $(\beta=-0.08, t=-0.9, p>0.10)$, but support H5a by indicating a significantly positive effect of perceived resources $(\beta=0.26, t=2.7, p<0.05)$ on CLA.

[Insert Table 3 about here] 
The interaction effect of openness to experience and power. With the main effects of openness to experience and power supported, we now turn our attention to the effect of the interaction between them on CLA (H3). As expected, this hypothesis is supported by a significantly positive effect of the interaction between openness to experience and power on $\operatorname{CLA}(\beta=0.21, t=2.5, p<0.05)$.

Moderating effects. Finally, this study tests the moderating effects of social norms and perceived resources on the relationships between openness to experience, power and CLA. H4b proposed that the positive association between openness to experience and CLA would be weaker when social norms increase. As expected, this hypothesis is supported by a significantly negative effect of the interaction between openness to experience and social norms on CLA ( $\beta=$ $-0.21, t=-2.4, p<0.05)$. Finally, H5b suggested that perceived resources would have a positive moderating effect on the association between power and CLA. The results support H5b, showing that the positive effect of perceived resources on CLA is bolstered for consumers with higher levels of perceived resources $(\beta=0.15, t=2.0, p<0.05)$. Finally, the addition of the interactions increases the explained variance of CLA by $44.4 \%$.

\section{Discussion}

This study discusses and tests how and why the combination of openness to experience (a personality trait) and power (a personal value trait) influence choice of luxury attributes (CLA) for branded products in Vietnam. The proposed hypotheses are tested by structural equation modelling for latent variables (Aiken and West, 1991; Ping, 1996). The results indicate the reliability and validity of the constructs and the findings support six in nine hypotheses proposed. Both openness to experience and power are found to have direct and interactive effects on CLA. In particular, the effect of openness to experience is weakened by the negative moderator effect of social norms, but the effect of power is strengthened by the positive moderator effect of 
perceived resources. The inclusion of interactions increases the explained variance of the choice of luxury product attributes from about $25 \%$ to about $36 \%$. Therefore, this study confirms that the phenomenon of luxury consumption was only fully understood by combining not only individuals' traits and personal values, but also social factors and consumers' perceived resources.

\section{Theoretical implications}

Openness to experience and power are shown to be variables that have a positive influence on CLA. The findings support the call to consider luxury product attributes based on consumers' personality and personal value traits (Amatulli and Guido, 2011; Graeff, 1997; Heine, 2009; Park et al., 2008; Pitts and Woodside, 1991; Shukla et al., 2015; Truong and McColl, 2011; Yim and Sauer, 2014). Although the associations between different types of personal value and/or personality traits and luxury consumption have been discussed and tested in some studies (Amatulli and Guido, 2011; Giovannini et al., 2015; Heine, 2009; Park et al., 2008; Shukla et al., 2015; Truong and McColl, 2011), this study contributes by testing and providing empirical evidence supporting the combined effects of openness to experience and power on CLA. These findings are important because the direct effects of openness to experience and power and especially the effect of the interaction between these two constructs on CLA have not previously been tested empirically. The findings thus support the interactional perspective of the relationship between personality and personal values (Bilsky and Schwartz, 1994; Parks and Guay, 2009) in relation to luxury attitudes and/or behaviors (Mulyanegara and Tsarenko, 2009).

It is noteworthy that most previous studies explored the link between personal traits/values and luxury consumption at a brand or product level (e.g., Amatulli and Guido, 2011; Giovannini et al., 2015; Heine, 2009; Truong and McColl, 2011) or just for a few luxury attributes (Holt and Cameron, 2010; Matzler et al., 2006; Miller and Mills, 2012; Olver and Mooradian, 2003; 
Solomon and Douglas, 1987). By developing a reflective second-order construct of luxury attributes, this study extends previous studies to capture the innovative and creative dimension (Holt and Cameron, 2010; Miller and Mills, 2012) in addition to three traditional dimensions (functional, experiential, symbolic interactional) (Berthon et al., 2009; Vickers and Renand, 2003). Based on this multiple dimension construct, this study provides a more comprehensive view of luxury attributes. More importantly, the measurement of the choice of luxury product attributes (CLA) allows to integrate the content of mediators, such as prestige, and simultaneously to separate the two-component structure of person-brand fit into personal traits and brand attributes. The separation generates opportunities to explore what kinds of personal traits and values fit with what kind of luxury attributes of a brand/product. This provides a clearer and deeper explanation for how and why customers choose or reject a (luxury) branded product (e.g., Matzler et al., 2011).

Although the interactive potential between personality and personal values to influence consumer behaviors has been discussed (Bilsky and Schwartz, 1994; Parks and Guay, 2009), empirical evidence is very rare. In addition, with different kinds of personality and value traits found in the literature, how a personality trait interacts with a value trait to influence consumers' attitudes and behavior is unclear. The findings of this study have indicated that for explaining a certain behavior, such as CLA, the exploration of such an interaction (e.g., between openness and power) needs to be considered under the corresponding perspectives. This requires that not only do both personality and value traits have to fit with corresponding behavioral characteristics, but also they have to have a mutual relationship or to cancel each other out (Bilsky and Schwartz, 1994; Roccas et al., 2002). Therefore, although our findings are limited to exploring the interaction of only one pair of personality and value traits, this opens the potential to explore further for other individual traits of personality and personal values. 
By integrating interactive perspectives (Amabile, 1996) and attitude theories (McMillan and Conner, 2003; Umeh and Patel, 2004), this study finds a negative moderating effect of social norms on the association between the openness to experience trait and CLA. This means that the manifestation of the trait in consumers' social lives is complex and lies in complying with the expectations of others (Olsen and Grunert, 2010). This result is consistent with the findings of Escalas and Bettman (2005). These authors showed that consumers form self-brand connections partly to construct their self-concepts and that brands with attributes consistent with an in-group perspective enhance self-brand connections for all consumers, whereas brands with attributes that are consistent with an out-group perspective have a stronger negative effect on independent versus interdependent consumers. However, their study tested the differences in self-brand connections as constructs rather than the differences in the relationships between personality traits and brand choice between groups. Therefore, the empirical evidence for the moderating role of social norms in the association between openness to experience and CLA found in this study is important and unique. However, this study fails to find a moderating effect of social norms in the association between power and CLA. This may be because the global luxury market has been experiencing substantial growth in recent years and luxury products have infiltrated the middle and even lower classes in most countries, resulting in a phenomenon termed the “democratization of luxury" (Nueno and Quelch, 1998). Therefore, the people in this developing country seem to be adopting material values such as possessing luxury products, at least for the rich and high social classes.

The association between power and CLA has to our knowledge not previously been tested in the consumer luxury literature. The findings contributed in this study indicate that perceived resources positively moderate the effect of power on CLA. The results support the value activation perspective (Higgins, 1996), as well as the theory of resource allocation (Roberts and 
Dant, 1991) and are consistent with a few previous studies explaining the link between personal values and behavior moderated by resources (Chen et al., 2001; Lönnqvist et al., 2011). However, this study fails to find a moderating effect of perceived resources in the association between openness to experience and CLA. This may be because perceived resources in this study may not be sufficiently strong to activate this personality trait, in particular as consumers' perceived resources in the sample is at a moderate level. A greater resource allocation for other traits, such as power in this case, may result in a lower resource allocation for the openness to experience trait, reducing the role of perceived resources in activating this personality trait.

The integration of the moderators of social norms and perceived resources has generated a more comprehensive understanding about how and why a personal trait could be activated to conduct a corresponding behavior, such as CLA. This approach helps to overcome the shortcomings of weak associations between personal traits and behaviors as found by some previous studies (e.g., Amatulli and Guido, 2011; Mulyanegara and Tsarenko, 2009; Park, Rabolt and Jeon, 2008; Yim and Sauer, 2014). More importantly, it shows the ways that consumers manage to pursue their goals to fulfil their personality or value traits. Our finding implies that Vietnamese consumers tend to consider the congruence (or incongruence) of social norms with their personality (e.g., openness) in conducting (or delaying) a buying behavior, while they tend to consider the pursuit of a value trait (e.g., power) as an individual issue in the same buying behavior. This may come from the difference between the apparent nature of personality traits and the latent nature of personal value traits in consumer life (Parks-Leduc et al., 2015).

\section{Practical implications}

This study has some important implications for the marketing of luxury products. The findings that openness to experience and power have a combined effect on CLA are of potential importance in positioning a luxury product when exploring and attempting to occupy market 
segments, suggesting that these personality and personal value traits should be considered. In addition, because consumers must have different scores on openness to experience and power traits, creating different nuance pairs of traits and encouraging customers to rank where they stand with those pairs of traits is important to help them find key product attributes that fit with their traits. Following this approach, firms should develop different product elements with different levels of luxury product features, which helps customers determine which combination of features best suits them. This strategy is expected to increase the participation of customers in creating product value and to push up the application of customized marketing in both online and offline business practices.

In addition, the fact that social norms are found to moderate the association between openness to experience and CLA shows that consumers manifest their personalities in choosing luxury attributes moderated by complying with social influences. This means that consumers manifest the openness trait strongly or weakly in their CLA depending on the consequences of their choice in terms of social punishments or rewards. Thus, a luxury product that is positioned with attributes in a target segment that fulfil both openness to experience trait and comply with social norms would have a higher probability of success. For example, a wife who is openness to experience wanting to buy a luxury purse will come across an obstacle if her husband or children protest or exhibit a negative attitude. Therefore, marketing managers need not only to understand consumers' openness to experience trait, but also to understand how and why this trait interacting with social norms are integrated in consumers' consideration process in choosing a specific luxury product.

Finally, the finding of a positive moderating effect of perceived resources on the association between power and CLA emphasizes the material conditions needed to satisfy the power trait through consumer shopping. This is important from a practical perspective as materialism shows 
a tendency to spread strongly in the context of the Vietnamese market. In particular, previous studies have indicated that materialists tend to use money to enhance their social status and to consume luxury items that can symbolize membership or desired membership in social groups (Fitzmaurice and Comegys, 2006). Besides power, consumers may also pursue other personal values. Therefore, managerial attention should not only focus on the levels of absolute (perceived) resources consumers have, but also on the relative (perceived) resources consumers will commit in relation to power and other personal values. An increase in allocated absolute or relative resources for power may facilitate its consequences (e.g., buying a luxury product) and vice versa (e.g., buying a non-luxury product). In addition, in view of the dynamic nature of (perceived) resources, a firm focusing on a segment with a strong power trait will need to monitor changes in consumers' resources, as well as their tendencies towards resource allocation, to position or reposition their luxury products with attributes congruent with the power trait and such trends.

\section{Limitations and future research}

This study has several limitations. The research is based on a relatively small convenience sample in Vietnam and focuses on a selection of luxury branded products without mentioning any specific brand. Future research should be extended to incorporate a more representative sample as well as testing them in other countries. Future research should also use specific premium or luxury brands, such as Samsung or Mercedes, or more extreme luxury brands, such as Louis Vuitton or Rolex. The study does not consider other personality traits (e.g., extroversion; McCrae and Costa, 1997) or personal value traits (e.g., achievement; Schwartz, 1992) affecting CLA, or indeed other dimensions of luxury branding, such as brand loyalty or equity (Keller, 2009). Thus, future studies should extend the model to gain a more comprehensive picture of consumers' choice of luxury products/brands. For example, openness 
to experience was found to relate with the values of stimulation $(+)$, self-direction $(+)$, universalism (+), conformity (-), tradition (-), and security (-) (Parks-Leduc et al., 2015). Therefore, an exploration of its interactions with these value traits would benefit from future studies. Future studies should also be extended to include different kinds of social norms, such as descriptive norms, personal norms or group norms (Escalas and Bettman, 2005), and different kinds of individual resources (e.g., time; Mathieson et al., 2001). Finally, the results presented here are based on self-reported measures of the constructs using correlation methods and thus the causal nature of the relationships is problematic.

\section{References}

Aiken, L.S. and West, S.G. (1991), Multiple Regression: Testing and Interpreting, Sage, Thousand Oaks, CA.

Ajzen, I. (1991), “The theory of planned behavior", Organizational Behavior and Human Decision Processes, Vol. 50 No. 2, pp. 179-211.

Amabile, T.M. (1996), Creativity in Context, Westview Press, Boulder, CO.

Amatulli, C. and Guido, G. (2011), “Determinants of purchasing intention for fashion luxury goods in the Italian market: A laddering approach", Journal of Fashion Marketing and Management, Vol. 15 No. 1, pp. 123-136.

Anderson, J.C. and Gerbing, D.W. (1984), “The effect of sampling error on convergence, improper solutions, and goodness-of-fit indices for maximum likelihood confirmatory factor analysis", Psychometrika, Vol. 49 No. 2, pp. 155-173.

Anderson, J.C. and Gerbing, D.W. (1988), "Structural equation modelling in practice: A review and recommended two step approach", Psychological Bulletin, Vol. 103 No. 3, pp. 411-423.

Bagozzi, R.P. and Yi, Y. (2012), "Specification, evaluation, and interpretation of structural equation models", Journal of the Academy Marketing Science, Vol. 40 No. 1, pp. 8-34. 
Ballantyne, R., Warren, A. and Nobbs, K. (2006), "The evolution of brand choice”, Journal of Brand Management, Vol. 13 No. 4/5, pp. 339-352.

Berthon, P., Pitt, L., Parent, M. and Berthon, J. (2009), “Aesthetics and ephemerality: Observing and preserving the luxury brand", California Management Review, Vol. 52 No. 1, pp. 45-66.

Bilsky, W. and Schwartz, S.H. (1994), "Values and personality", European Journal of Personality, Vol. 8 No. 3, pp. 163-181.

Breininge, J.C. (2015), “Appetite for luxury in Vietnam: A lucrative market for high-end products", Vietnam Briefing, 16th April (http://www.vietnam-briefing.com/news/appetiteluxury-vietnam-lucrative-market-highend-products.html/).

Chen, S., Lee-Chai, A.Y. and Bargh, J.A. (2001), "Relationship orientation as moderator of the effects of social power", Journal of Personality and Social Psychology, Vol. 80 No. 2, pp. $183-187$.

Chen, J. and Kim, S. (2013), “A comparison of Chinese consumers' intentions to purchase luxury fashion brands for self-use and for gifts", Journal of International Consumer Marketing, Vol. 25 No. 1, pp. 29-44.

Cong, L.C., Olsen, S.O. and Tuu, H.H. (2012), "The roles of ambivalence, choice conflict and family identity: A study of food choice among Vietnamese consumers", Food Quality and Preference, Vol. 28 No. 1, pp. 92-100.

Costa, P.T.Jr. and McCrae, R.R. (1985), The NEO Personality Inventory Manual, Odessa, FL: Psychological Assessment Resources.

Costa, P.T.Jr. and McCrae, R.R. (1992), Revised NEO Personality Inventory (NEO PI-R) and NEO Five-Factor Inventory (NEO-FFI) Professional Manual, Psychological Assessment Resources, Odessa, FL. 
Donnellan, M.B., Frederick, O.L., Brendan, B.M. and Richard, L.E. (2006), “The mini-IPIP scales: Tiny-yet-effective measures of the big five factors of personality", Psychological Assessment, Vol. 18 No. 2, pp. 192-203.

Dubois, B., Czellar, S. and Laurent, G. (2005), "Consumer segments based on attitudes toward luxury: Empirical evidence from twenty countries", Marketing Letters, Vol. 16 No. 2, pp. $115-128$.

Ebay (2015), "How to choose a luxury watch that fits your personality", Ebay, 4th March, (http://www.ebay.com/gds/How-to-choose-a-luxury-watch-that-fits-your-personality/10000000195420640/g.html).

Escalas, J.E. and Bettman, J.R. (2005), "Self-construal, reference groups, and brand meaning”, Journal of Consumer Research, Vol. 32 No. 3, pp. 378-389.

Fitzmaurice, J. and Comegys, C. (2006), “Materialism and social consumption”, Journal of Marketing Theory \& Practice, Vol. 14 No. 4, pp. 287-299.

Fornell, C. and Larcker, D.F. (1981), “Evaluating structural equation models with unobservable variables and measurement error", Journal of Marketing Research, Vol. 18 No. 1, pp. 39-50.

George, J.M. and Zhou, J. (2001), "When openness to experience and conscientiousness are related to creative behavior: An interactional approach", Journal of Applied Psychology, Vol. 86 No. 3, pp. 513-524.

Giovannini, S., Xu, Y. and Thomas, J. (2015), “Luxury fashion consumption and Generation Y consumers: Self, brand consciousness, and consumption motivations", Journal of Fashion Marketing and Management, Vol. 19 No. 1, pp. 22-40.

Goldberg, L.R. (1992), “The development of markers of the big-five factor structure”, Psychological Assessment, Vol. 4 No. 1, pp. 26-42. 
Gosling, S.D., Rentfrow, P.J. and Swann, W.B.Jr. (2003), “A very brief measure of the big five personality domains", Journal of Research in Personality, Vol. 37 No. 6, pp. 504-528.

Graeff, C.L. (1997), "Evolution of situational leadership theory: A critical review”, Leadership Quarterly, Vol. 8 No. 2, pp. 153-171.

Hair, J.F. Jr., Black, W.C., Babin, B.J. and Anderson, R.E. (2010), Multivariate Data Analysis, Seventh Edition, Pearson Prentice Hall.

Heine, K. (2009), "Using personal and online repertory grid methods for the development of a luxury brand personality", The Electronic Journal of Business Research Methods, Vol. 7 No. 1, pp. $25-30$.

Higgins, E.T. (1996), "The 'self-digest': Self-knowledge serving self-regulatory functions", Journal of Personality and Social Psychology, Vol. 71 No. 6, pp. 1062-1083.

Holt, D. and Cameron, D. (2010), Cultural Strategy: Using Innovative Ideologies to Build Breakthrough Brands, Oxford University Press, Oxford.

Iacobucci, D. (2010), “Structural equations modeling: Fit indices, sample size, and advanced topics”, Journal of Consumer Psychology, Vol. 20 No. 1, pp. 90-98.

Kapferer, J-N. and Bastien, V. (2009), “The specificity of luxury management: Turning marketing upside down", Journal of Brand Management, Vol. 16 No. 5/6, pp. 311-322.

Keller, K.L. (2009), “Managing the growth trade-off: challenges and opportunities in luxury branding”, Journal of Brand Management, Vol. 16 No. 5/6, pp. 290-301.

Kline, R.B. (2010), Principles and Practice of Structural Equation Modeling, Guilford Press, New York, USA.

Kotler, P. (2000), Marketing Management: Millenium Edition, Pearson, Boston, USA.

Johnson, M.D. (1989), “The differential processing of product category and noncomparable choice alternatives", Journal of Consumer Research, Vol. 16 No. 3, pp. 300-309. 
Lönnqvist, J-E., Walkowitz, G., Verkasalo, M. and Wichardt, P.C. (2011), “Situational power moderates the influence of self-transcendence vs. self-enhancement values on behavior in ultimatum bargaining", Journal of Research in Personality, Vol. 45 No. 3, pp. 336-339.

Marsh, H.W. and Hau, K.T. (1999), “Confirmatory factor analysis: Strategies for small sample sizes”, in Hoyle, R.H. (Ed.), Statistical Strategies for Small Sample Research (pp. 252-284), Thousand Oaks, CA: Sage.

Mathieson, K., Peacock, E. and Chin, W.W. (2001), "Extending the technology acceptance model: the influence of perceived user resources", Advances in Information Systems, Vol. 32 No. 3, pp. 86-112.

Matzler, K., Bidmon, S. and Grabner-Krauter, S. (2006), "Individual determinants of brand affect: The role of the personality traits of extroversion and openness to experience", Journal of Product \& Brand Management, Vol. 15 No. 7, pp. 427-434.

Matzler, K., Pichler, E., Füller, J. and Mooradian, T.A. (2011), "Personality, person-brand fit, and brand community: An investigation of individuals, brands, and brand communities", Journal of Marketing Management, Vol. 27 No 9/10, pp. 874-890.

McCrae, R.R. and Costa, P.T. (1997), "Personality trait structure as a human universal", American Psychologist, Vol. 52 No. 5, pp. 509-516.

McMillan, B. and Conner, M. (2003), “Applying an extended version of theory of planned behavior to illicit drug use among students", Journal of Applied Social Psychology, Vol. 33 No. 8, pp. 1662-1683.

Miller, K.W. and Mills, M.K. (2012), "Contributing clarity by examining brand luxury in the fashion market", Journal of Business Research, Vol. 65 No. 10, pp. 1471-1479. 
Mulyanegara, R.C. and Tsarenko, Y. (2009), "Predicting brand choices: An examination of the predictive power of consumer personality and values in the Australian fashion market", Journal of Fashion Marketing and Management, Vol. 13 No. 3, pp. 358-371.

Nedungadi, P. (1990), "Recall and consumer consideration sets: Influencing choice without altering brand evaluations", Journal of Consumer Research, Vol. 17 No. 3, pp. 263-276.

Nueno, J.L. and Quelch, J.A. (1998), “The mass marketing of luxury”, Business Horizons, Vol. 41 No. 6, pp. 61-68.

Okonkwo, U. (2009), "Sustaining the luxury brand on the internet", Journal of Brand Management, Vol. 16 No. 5/6, pp. 302-310.

Olsen, S.O. and Grunert, K.G. (2010), “The role of satisfaction, norms and conflict in families' eating behavior", European Journal of Marketing, Vol. 44 No. 7/8, pp. 1165-1181.

Olver, J.M. and Mooradian, T.A. (2003), "Personality traits and personal values: A conceptual and empirical integration", Personality and Individual Differences, Vol. 35 No. 1, pp. 109125.

Park, H.J., Rabolt, N.J. and Jeon, K.S. (2008), "Purchasing global luxury brands among young Korean consumers", Journal of Fashion Marketing Management, Vol. 12 No. 2, pp. 244259.

Parks-Leduc, L., Feldman, G. and Bardi, A. (2015), "Personality traits and personal values: A meta-analysis", Personality and Social Psychology Review, Vol. 19 No. 1, pp. 3-29.

Parks, L. and Guay, R.P. (2009), "Personality, values, and motivation", Personality and Individual Differences, Vol. 47 No.7, pp. 675-684.

Peterson, R.S., Smith, D.B., Martorana, P.V. and Owens, P.D. (2003), "The impact of chief executive officer personality on top management team dynamics: One mechanism by which 
eadership affects organizational performance", Journal of Applied Psychology, Vol. 88 No. 5, pp. 795-808.

Ping, R.A.Jr. (1996), "Latent variable interaction and quadratic effect estimation: A two-step technique using structural equation analysis”, Psychological Bulletin, Vol. 119 No. 1, pp. $166-175$.

Pitts, R.E. and Woodside, A.G. (1991), “Examining the structure of personal values and consumer decision making”, Journal of Business Research, Vol. 22 No. 1, pp. 91-93.

Roberts, S.D. and Dant, R.P. (1991), "Rethinking resource allocation in modern society: A meanings-based approach”, Journal of Economic Psychology, Vol. 12 (March), pp. 11-429.

Roccas, S., Sagiv, L., Schwartz, S.H. and Knafo, A. (2002), “The Big Five Personality factors and personal values", Personality and Social Psychology Bulletin, Vol. 28 No. 6, pp. 789801.

Schwartz, S.H. (1992), "Universals in the content and structure of values: Theoretical advances and empirical tests in 20 countries", Advances in Experimental Social Psychology, Vol. 25, pp. $1-65$.

Shukla, P., Singh, J. and Banerjee, M. (2015), “They are not all same: Variations in Asian consumers' value perceptions of luxury brands", Marketing Letters, Vol. 25 No. 3, pp. 265278.

Sirgy, M.J., Johar, J.S., Samli, A.C. and Claiborne, C.B. (1991), "Self-congruity versus functional congruity: Predictors of consumer behavior", Journal of the Academy of Marketing Sciences, Vol. 19 No. 4, pp. 363-375.

Solomon, M.R. and Douglas, S.P. (1987), "Diversity in product symbolism: The case of female executive clothing”, Psychology \& Marketing, Vol. 4 No. 3, pp. 189-212. 
Steenkamp, J.E.M. \& Van Trijp, H.C.M. (1991), “The use of LISREL in validating marketing constructs”, International Journal of Research in Maketing, Vol. 8, pp. 283-299.

Stern, P.C., Dietz, T. and Guagnano, G.A. (1998), “A brief inventory of values”, Educational and Psychological Measurement, Vol. 58 No. 6, pp. 984-1001.

Tsai, S. (2005), "Impact of personal orientation on luxury-brand purchase value”, International Journal of Market Research, Vol. 47 No. 4, pp. 429-454.

Truong, Y. and McColl, R. (2011), “Intrinsic motivations, self-esteem, and luxury goods consumption", Journal of Retailing and Consumer Services, Vol. 18 No. 6, pp. 555-561.

Tuu, H.H. and Olsen, S.O. (2010), "Nonlinear effects between satisfaction and loyalty: An empirical study of different conceptual relationships", Journal of Targeting, Measurement and Analysis for Marketing, Vol. 18 No. 3/4, pp. 239-251.

Umeh, K. and Patel, R. (2004), "Theory of planned behavior and ecstasy use: An analysis of moderator-interactions", British Journal of Health Psychology, Vol. 9 No. 1, pp. 25-38.

Verplanken, B. and Holland, R.W. (2002), "Motivated decision-making: Effects of activation and self-centrality of values on choices and behavior", Journal of Personality and Social Psychology, Vol. 82 No. 3, pp. 434-447.

Vickers, J.S. and Renand, F. (2003), “The marketing of luxury goods: an exploratory study”, Marketing Review, Vol. 3 No. 4, pp. 459-478.

Vigneron, F. and Johnson, L.W. (1999), “A review and a conceptual framework of prestigeseeking consumer behavior", Academy of Marketing Science Review, Vol. 99 No. 1, pp. 115.

Vigneron, F. and Johnson, L.W. (2004), "Measuring perceptions of brand luxury", The Journal of Brand Management, Vol. 11 No. 6, pp. 484-506. 
Vinson, D.E., Scott, J.E. and Lamont, L.M. (1977), “The role of personal values in marketing and consumer behavior", Journal of Marketing, Vol. 41 No. 2, pp. 44-50.

Wiedmann, K-P., Hennigs, N. and Siebels, A. (2007), “Measuring consumers' luxury value perception: A cross-cultural framework”, Academy of Marketing Science Review, Vol. 7 No. 7, pp. 333-361.

Wong, N.Y. and Ahuvia, A.C. (1998), "Personal taste and family face: Luxury consumption in Confucian and Western societies", Psychology \& Marketing, Vol. 15 No. 5, pp. 423-432.

Yim, M.Y.C. and Sauer, P.L. (2014), "Drivers of attitudes toward luxury brands: A crossnational investigation into the roles of interpersonal influence and brand consciousness", International Marketing Review, Vol. 31 No. 4, pp. 363-389.

Zou, D., Jin, L., He, Y. and Xu, Q. (2014), “The effect of the sense of power on Chinese consumers' uniqueness-seeking behavior", Journal of International Consumer Marketing, Vol. 26 No. 1, pp. 14-28. 


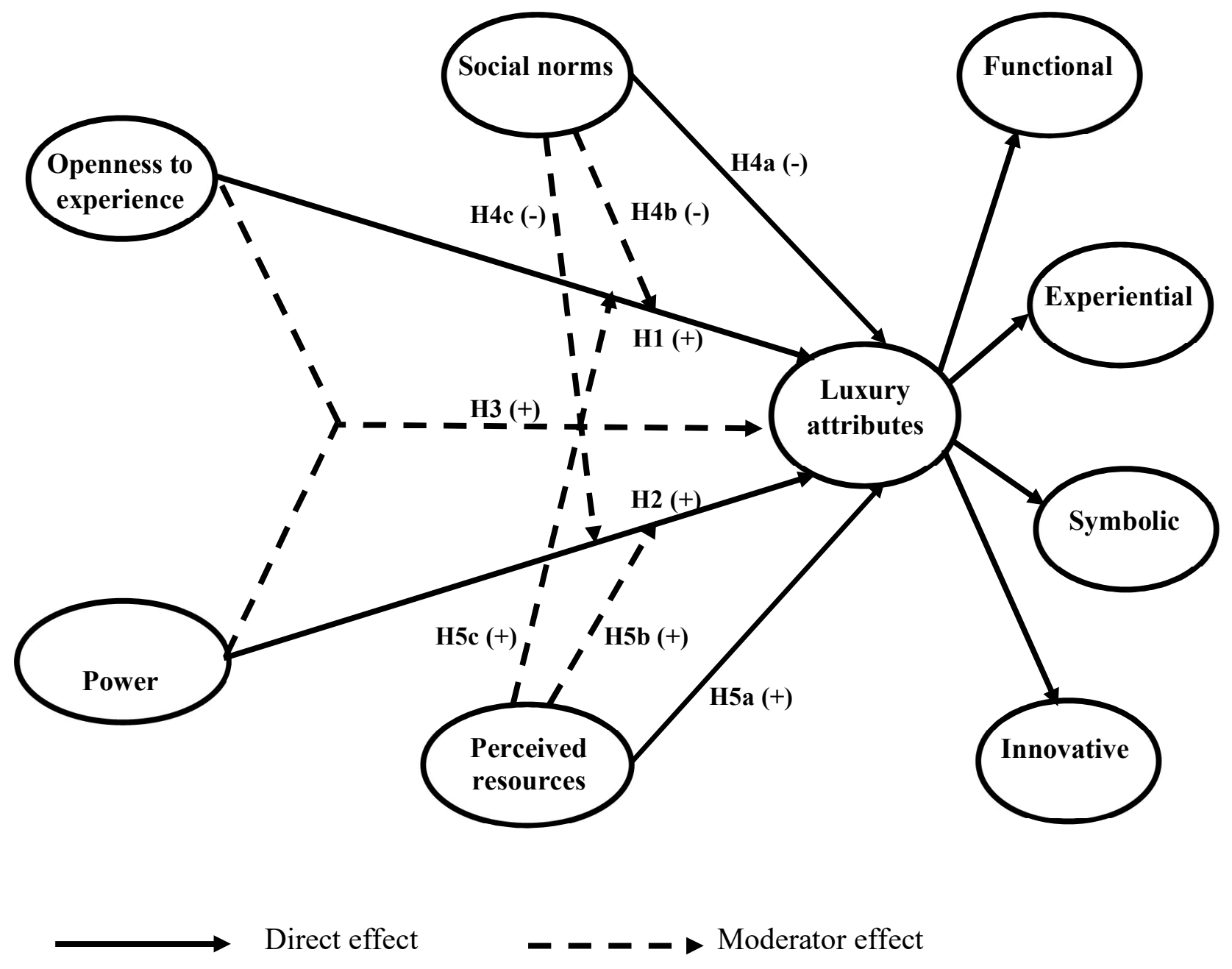

Figure 1: The theoretical model 


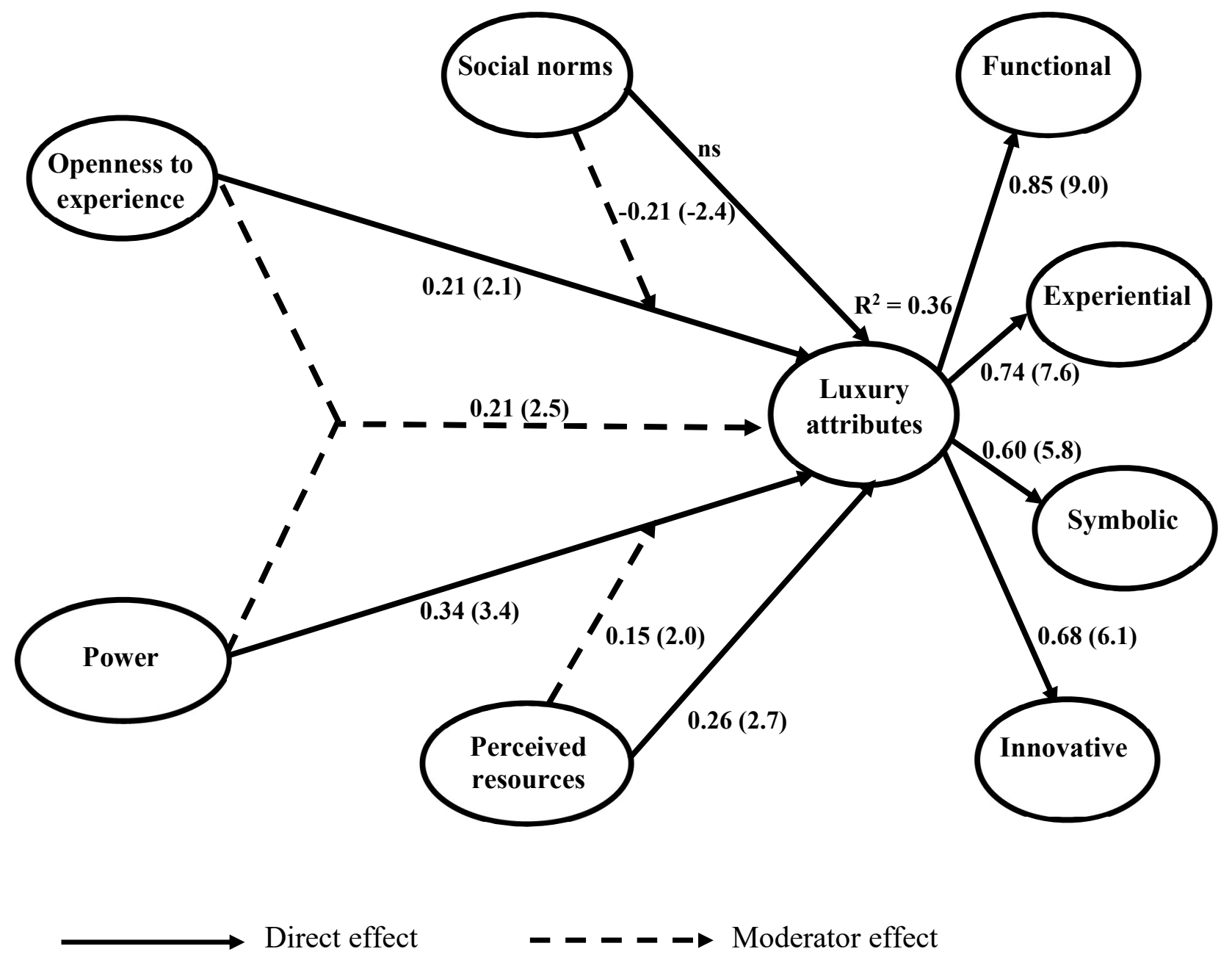

Figure 2: Analyzed path model

Notes. $t$-values are in paratheses 
Table 1. Constructs and indicators

\begin{tabular}{|c|c|c|c|c|c|}
\hline Constructs and indicators & $\begin{array}{l}\text { Factor } \\
\text { loadings }\end{array}$ & $\begin{array}{c}t \\
\text { values }\end{array}$ & $\begin{array}{c}\text { Cronbach's } \\
\text { Alpha }\end{array}$ & $\begin{array}{l}\text { Composite } \\
\text { reliability }\end{array}$ & $\begin{array}{l}\text { Variance } \\
\text { extracted }\end{array}$ \\
\hline Functional attributes (Functional) & & & 0.90 & 0.85 & 0.65 \\
\hline Low/high quality & 0.76 & 12.2 & & & \\
\hline Simple/sophisticated & 0.96 & 17.4 & & & \\
\hline Humble/superior & 0.68 & 8.4 & & & \\
\hline Experiential attributes (Experiential) & & & 0.77 & 0.75 & 0.50 \\
\hline Popular/rare & 0.69 & 9.0 & & & \\
\hline Unattractive/attractive & 0.73 & 11.5 & & & \\
\hline Normal/unique & 0.70 & 9.3 & & & \\
\hline Symbolic attributes (Symbolic) & & & 0.78 & 0.76 & 0.51 \\
\hline Low social level/high social level & 0.73 & 11.1 & & & \\
\hline Targeted at poor/rich people & 0.65 & 8.1 & & & \\
\hline Low symbolic value/high symbolic value & 0.76 & 11.8 & & & \\
\hline Innovative attributes (Innovative) & & & 0.72 & 0.71 & 0.56 \\
\hline Low/high innovation & 0.64 & 8.4 & & & \\
\hline Low creative/high creativity & 0.84 & 13.1 & & & \\
\hline Openness to experience I see myself as... & & & 0.74 & 0.72 & 0.46 \\
\hline ... creative & 0.69 & 9.3 & & & \\
\hline ... imaginative & 0.68 & 9.1 & & & \\
\hline ... open to new experiences, complex & 0.67 & 9.0 & & & \\
\hline Power & & & 0.78 & 0.75 & 0.50 \\
\hline Wealth & 0.76 & 10.6 & & & \\
\hline Authority & 0.61 & 8.5 & & & \\
\hline Control over people and resources & 0.75 & 10.5 & & & \\
\hline Perceived resources & & & 0.91 & 0.89 & 0.74 \\
\hline Money & 0.84 & 14.4 & & & \\
\hline Knowledge & 0.97 & 18.2 & & & \\
\hline Social power & 0.76 & 12.5 & & & \\
\hline Social norms & & & 0.79 & 0.76 & 0.52 \\
\hline Friends & 0.75 & 10.7 & & & \\
\hline Colleagues & 0.73 & 10.1 & & & \\
\hline Social community, social network & 0.68 & 8.9 & & & \\
\hline Second-order construct of CLA ${ }^{a}$ & & & - & 0.81 & 0.52 \\
\hline Functional & 0.85 & 9.0 & & & \\
\hline Experiential & 0.74 & 7.6 & & & \\
\hline Symbolic & 0.60 & 5.8 & & & \\
\hline Innovative & 0.68 & 6.1 & & & \\
\hline
\end{tabular}

Notes. All factor loadings are significant at $p<0.001 ;{ }^{a}$ A separate CFA is conducted for the reflective second-order construct of CLA. 
Table 2. Construct means, standard deviations and correlations

\begin{tabular}{lccccccc}
\hline Constructs & $\mathrm{M}$ & $\mathrm{SD}$ & 1 & 2 & 3 & 4 & 5 \\
\hline 1. CLA & 4.63 & 1.15 & 1.00 & 0.48 & 0.51 & 0.63 & 0.52 \\
2. Openness & 5.26 & 1.05 & 0.22 & 1.00 & 0.47 & 0.56 & 0.48 \\
3. Power & 3.62 & 1.88 & 0.38 & $0.02^{\mathrm{ns}}$ & 1.00 & 0.62 & 0.51 \\
4. Perceived resources & 3.02 & 1.48 & 0.34 & $0.04^{\mathrm{ns}}$ & 0.30 & 1.00 & 0.63 \\
5. Social norms & 3.20 & 1.25 & $0.12^{\mathrm{ns}}$ & 0.27 & $0.15^{\mathrm{ns}}$ & 0.42 & 1.00
\end{tabular}

Notes. ${ }^{\text {ns }}$ non-significant; the values of AVE are above the diagonal. 
Table 3. Testing hypotheses

\begin{tabular}{|c|c|c|c|c|c|c|}
\hline \multirow{2}{*}{\multicolumn{3}{|c|}{ Variables/hypotheses/results (Supported/Not) }} & \multicolumn{2}{|c|}{$\begin{array}{c}\text { Direct Effect } \\
\text { Model (DEM) }\end{array}$} & \multicolumn{2}{|c|}{$\begin{array}{l}\text { Full Model } \\
\text { (FM) }\end{array}$} \\
\hline & & & \multirow{2}{*}{$\begin{array}{c}\text { Std. } \beta \\
0.23^{*}\end{array}$} & \multirow{2}{*}{$\begin{array}{r}t \text {-values } \\
2.2\end{array}$} & \multirow{2}{*}{$\begin{array}{l}\text { Std. } \beta \\
0.21^{*}\end{array}$} & \multirow{2}{*}{$\begin{array}{r}t \text {-values } \\
2.1\end{array}$} \\
\hline Openness & H1 & Supported & & & & \\
\hline Power & $\mathrm{H} 2$ & Supported & $0.31^{* *}$ & 3.0 & $0.34 * * *$ & 3.4 \\
\hline Social norms & $\mathrm{H} 4 \mathrm{a}$ & Not supported & $-0.10^{\mathrm{ns}}$ & -0.9 & $-0.08^{\mathrm{ns}}$ & -0.9 \\
\hline Perceived resources & $\mathrm{H} 5 \mathrm{a}$ & Supported & $0.28 * *$ & 2.8 & $0.26^{*}$ & 2.7 \\
\hline Openness x Power & $\mathrm{H} 3$ & Supported & - & - & $0.21 *$ & 2.5 \\
\hline Openness x Social norms & $\mathrm{H} 4 \mathrm{~b}$ & Supported & - & - & $-0.21 *$ & -2.4 \\
\hline Power x Perceievd resources & s H5b & Supported & - & - & $0.15^{*}$ & 2.0 \\
\hline $\mathrm{R}^{2} \mathrm{CLA}(\%)$ & & & 24.8 & & 35 & \\
\hline$\Delta \mathrm{R}^{2} \mathrm{CLA}(\%)$ & & & - & & 11. & \\
\hline Effect size (ES) & & & - & & 44 & \\
\hline Chi-square (df), Sig. & & 363.9 & 218), $p=0.0($ & & $489.3(282$ & $p=0.00$ \\
\hline GFI & & & 0.89 & & 0.8 & \\
\hline CFI & & & 0.91 & & 0.9 & \\
\hline IFI & & & 0.91 & & 0.5 & \\
\hline NFI & & & 0.90 & & 0.8 & \\
\hline AGFI & & & 0.88 & & 0.8 & \\
\hline RMSEA & & & 0.06 & & 0. & \\
\hline
\end{tabular}

Notes. ${ }^{*} p<0.05 ; * * p<0.01 ; * * * p<0.001 ;$ ns: non-significant;

$E S=\left(R_{Y, F M}^{2}-R_{Y, D E M}^{2}\right) /\left(1-R_{Y, F M}^{2}\right) ; Y=C L A$. 